\title{
Arctic and Antarctic Oscillation signatures in tropical coral proxies over the South China Sea
}

\author{
D.-Y. Gong ${ }^{1}$, S.-J. Kim ${ }^{2}$, and C.-H. Ho ${ }^{3}$ \\ ${ }^{1}$ State Key Laboratory of Earth Surface Processes and Resource Ecology, Beijing Normal University, Beijing, 100875, China \\ ${ }^{2}$ Korea Polar Research Institute, Incheon, Korea \\ ${ }^{3}$ School of Earth and Environmental Sciences, Seoul National University, Seoul, Korea
}

Received: 9 July 2008 - Revised: 25 March 2009 - Accepted: 14 April 2009 - Published: 4 May 2009

\begin{abstract}
Arctic Oscillation (AO) and Antarctic Oscillation (AAO) are the leading modes of atmospheric circulation in mid-high latitudes. Previous studies have revealed that the climatic influences of the two modes are dominant in extratropical regions. This study finds that $\mathrm{AO}$ and AAO signals are also well recorded in coral proxies in the tropical South China Sea. There are significant interannual signals of AO and AAO in the strontium ( $\mathrm{Sr}$ ) content, which represents the sea surface temperature (SST). Among all the seasons, the most significant correlation occurs during winter in both hemispheres: the strongest AO-Sr and AAO-Sr coral correlations occur in January and August, respectively. This study also determined that the $\mathrm{Sr}$ content lags behind $\mathrm{AO}$ and $\mathrm{AAO}$ by 1-3 months. Large-scale anomalies in sea level pressure and horizontal wind at $850 \mathrm{hPa}$ level support the strength of $\mathrm{AO} / \mathrm{AAO}$-coral teleconnections. In addition, a comparison with oxygen isotope records from two coral sites in neighboring oceans yields significant $\mathrm{AO}$ and $\mathrm{AAO}$ signatures with similar time lags. These results help to better understand monsoon climates and their teleconnection to high-latitude climate changes.
\end{abstract}

Keywords. Meteorology and atmospheric dynamics (Climatology; Paleoclimatology) - Oceanography: biological and chemical (Geochemistry)

\section{Introduction}

Arctic Oscillation (AO) and Antarctic Oscillation (AAO) are the leading modes in atmospheric circulation variability in the mid-high latitudes of the Northern and Southern Hemispheres. Due to zonal symmetry, they are also known as the

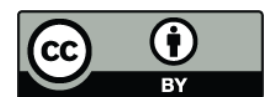

Correspondence to: D.-Y. Gong (gdy@bnu.edu.cn)
Northern Annular Mode and Southern Annular Mode, respectively. The two modes exert notable influences on regional climates in both hemispheres (Thompson and Wallace, 1998, 2000; Gong and Wang, 1998, 1999). Previous studies have indicated that the East Asian monsoon system is closely related to AO and AAO variations. During boreal winter and spring, a warmer temperature, smaller weather variances, less frequent cold surges, reduced dust storm frequency, and lighter sea-ice conditions are observed over the East Asian in high-AO years. Their relation are connected through atmospheric circulation systems such as the East Asian winter monsoon and Siberian High, and supported by station meteorological data (Gong et al., 2001; Wu and Wang, 2002; Gong and Ho, 2004; Jeong and Ho, 2005), as well as by the climate model simulation (Lu et al., 2007). Some researchers have determined that the Southern Hemisphere AAO is linked to climate variations in the East Asianwestern Pacific sector, including precipitation in southern China, weather extremes in northern China and tropical cyclones in the East China Sea (Nan and Li, 2003; Xue et al., 2004; Fan and Wang, 2004; Ho et al., 2005). However, the mechanisms of the correlation between AAO and the climate in Asian climates are not well understood. The majority of investigations focused on regional climates in the mid-high latitudes; few studies focused on the tropics. However, investigation of the climate response at low latitudes to $\mathrm{AO}$ and AAO is hampered by the limited availability of meteorological observations in tropical oceans. Satellite observations obtained over short time periods indicated that $\mathrm{AO}$ and AAO signals may be detectable in some low-latitude regions (Miller et al., 2003). Thompson and Lorenz (2004) showed the effects of $\mathrm{AO}$ and $\mathrm{AAO}$ on mean zonal winds in the upper troposphere of the tropics. However, little is known about the corresponding maritime climate anomalies in tropical East Asia (including the South China Sea), where ocean forcings are important components of monsoons with regard to tropic to mid-high latitude connection (Nitta and Hu, 1996;

Published by Copernicus Publications on behalf of the European Geosciences Union. 


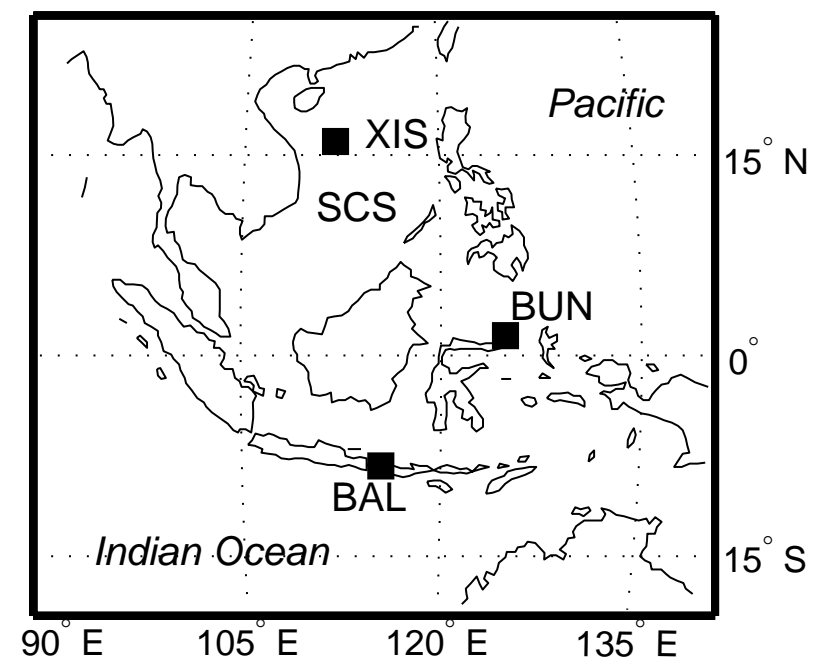

Fig. 1. Locations of coral proxies used in the study. XIS: Xisha, BAL: Bali, BUN: Bunaken; SCS: South China Sea.

Lau et al., 2000; Nakamura et al., 2006). Long-term climate proxy data collected from tropical oceans provided evidence of tropical response to AO and AAO. For example, Rimbu et al. (2001) identified AO signals in coral proxies in the Red Sea. In the East Asian tropics some oceanic proxies are available, which provide good indicators of sea temperature and/or precipitation. Preliminary investigations indicated that coral proxies in the South China Sea have a good relation with variations in historical East Asian monsoons (Peng et al., 2003). Considering this information, it would be interesting to determine the relation between $\mathrm{AO} / \mathrm{AAO}$ and climate proxies in tropical East Asia.

This study contains evidence of tropical AO and AAO signals as revealed in tropical coral proxies in the South China Sea. This would provide useful information for better understanding climate variations in tropical ocean and East Asia, as well as their possible responses to high-latitude climate changes.

\section{Data and methods}

This study primarily utilizes data pertaining to the monthly resolution strontium $(\mathrm{Sr})$ content in Porites coral collected from the Xisha site $\left(16^{\circ} \mathrm{N}, 112^{\circ} \mathrm{E}\right)$ in the South China Sea over a time span ranging from 1906 to 1994 (Sun et al., 2004) (Fig. 1). The open-ocean site, in the center of the South China Sea, is a good location from which to monitor summer monsoons(Liang et al., 2007). The influence of continental runoff and river flow at the site is expected to be minimal. The $\mathrm{Sr}$ content at the site serves as a good indicator of sea surface temperature (SST). From 1976 to 1994, Sr content and SST showed a negative correlation with a high value of the correlation coefficient, $r^{2}=0.96$ (Sun et al., 2004).
Because reliable oceanic/meteorological observations at the South China Sea have been conducted over a short time period, this study uses the original $\mathrm{Sr}$ content, instead of the SSTs/precipitation derived from the proxies, to avoid calibration uncertainty due to the short time period.

$\mathrm{AO}$ indices used in the study are the corresponding time coefficients of the first empirical orthogonal function of monthly sea level pressures (SLP) north of $20^{\circ} \mathrm{N}$ (Thompson and Wallace, 1998). The AAO indices are defined as the difference between the zonal mean sea level pressure at $40^{\circ} \mathrm{S}$ and that at $65^{\circ} \mathrm{S}$ (Gong and Wang, 1998, 1999). Because observations were limited, noticeable discontinuities in the monthly mean sea level pressure values were observed in the Southern Hemisphere (Marshall and Harangozo, 2000; Marshall, 2002) and Northern Hemisphere in the early period (Yang et al., 2002). In order to avoid erroneous correlation that could arise from data discontinuity, the study focuses only on inter-annual time-scale variability in both the coral proxy and climate variables. The analysis data periods are also confined to the most reliable reanalysis period since the late 1950s. The SLPs for defining AAO and lower troposphere wind fields are based on ERA40 reanalysis data sets (Uppala et al., 2005), available from September 1957 to August 2002, with a global spatial resolution of $2.5^{\circ}$ longitude $\times 2.5^{\circ}$ latitude. More significantly, ERA 40 data provides an improved representation of high-latitude atmospheric circulation variability in the Southern Hemisphere (Marshall, 2003). Note ERA40 is not a pure observation. To reduce the possible influence of the datasets on the AAO-Sr relations, two other SLPs were also compared: the NCEP/NCAR reanalysis, which is a different reanalysis dataset (Kalnay et al., 1996); and the HadSLP2 datasets, which is a global SLP interpolated from station observations (Allan and Ansell, 2006). The variability of SLPs over the Southern Hemisphere is diverse across different datasets. Jones and Lister (2007) compared four monthly SLP datasets for the Southern Hemisphere and found that the agreement among them is significantly dependent on the locations in the observing network. Most Southern Hemisphere stations began in the International Geophysical Year. Reanalysis data since 1957/58 would better represent the SLP field at southern mid-high latitudes.

Previous studies indicated that interannual variations in climate and proxies are significantly modulated by the El Niño/Southern Oscillation (ENSO) (Tudhope et al., 1995; Charles et al., 1997; Sun et al., 2004; Isoguchi and Kawamura, 2005). To highlight the $\mathrm{AO} / \mathrm{AAO}$ signature in proxies, the possible influence of ENSO should be excluded. In the western Pacific, regional climate variables usually lag behind ENSO signals by a few months. For example, from 1950 to 1993, Sr-SST values in November have a moderate correlation with the Niño3.4 SSTs in September $(r=+0.22)$ and October $(r=+0.23)$. Accordingly, the ENSO signals were removed from the $\mathrm{Sr}$ content time series. Here, the ENSO influence is estimated by linearly fitting with the Niño3.4 SSTs 


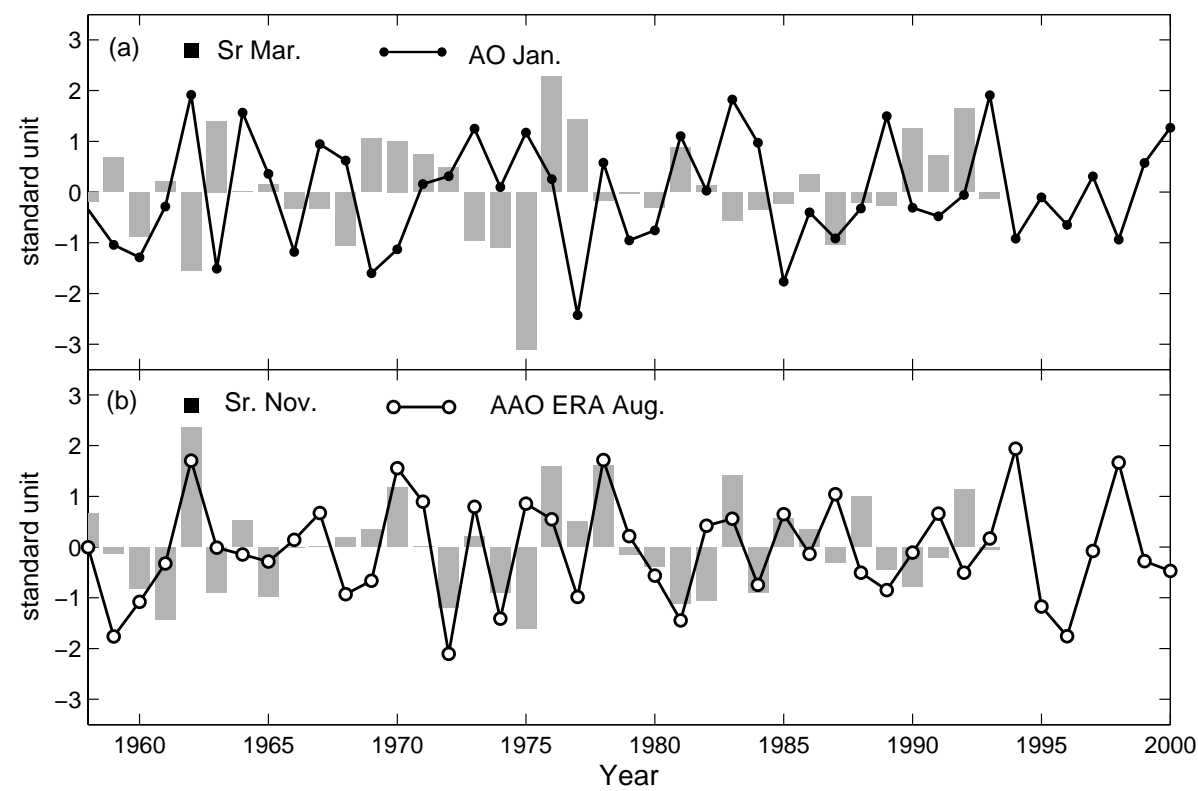

Fig. 2. Time-series for AO, AAO, and Sr for different months. (a) January AO and March Sr, (b) August AAO and November Sr. All timeseries are high-pass filtered and only interannual variations are shown.

Table 1. Correlation between the AO/AAO and the $\mathrm{Sr}$ content during the 1958-1993 data period for interannual time series with the Sr content lagging from 0 to 4 months.

\begin{tabular}{lccccc}
\hline & \multicolumn{5}{c}{ Sr content with time lags (months) } \\
& +0 & +1 & +2 & +3 & +4 \\
\hline January AO & $-0.32^{\mathrm{c}}$ & $-0.30^{\mathrm{c}}$ & $-0.46^{\mathrm{a}}$ & -0.18 & -0.26 \\
August AAO (HadSLP2) & +0.19 & $+0.30^{\mathrm{c}}$ & $+0.35^{\mathrm{b}}$ & $+0.40^{\mathrm{b}}$ & +0.19 \\
August AAO (NCEP/NCAR) & +0.13 & $+0.35^{\mathrm{b}}$ & $+0.39^{\mathrm{b}}$ & $+0.39^{\mathrm{b}}$ & +0.20 \\
August AAO (ERA40) & +0.14 & $+0.39^{\mathrm{b}}$ & $+0.42^{\mathrm{b}}$ & $+0.49^{\mathrm{a}}$ & +0.25 \\
\hline
\end{tabular}

${ }^{\mathrm{a}} p<0.01 ;{ }^{\mathrm{b}} p<0.05 ;{ }^{\mathrm{c}} p<0.1$.

of the preceding 0-3 months. Removing the ENSO signals from the Sr time series would help to improve the signal-tonoise ratio. In fact, the $\mathrm{AO} / \mathrm{AAO}$ signals were also checked using the original Sr-content time series and results were almost identical. The implication is that the robustness of the $\mathrm{AO} / \mathrm{AAO}-\mathrm{Sr}$ relation is somewhat independent of the ENSO phases.

In addition, as low frequencies exist in many climate proxies, misleading results are possible, potentially resulting in an apparent correlation even if these climate indices have no physical relation. It is more helpful to examine the possibility of a cause-and-effect explanation between climate and proxies by excluding long-term variations caused by various factors, including the influence of global warming on SST, Suess effect of coral isotope records, tectonic movement, and other factors. Therefore, prior to analysis, all variables are filtered using a Butterworth filter. Only high-frequency com- ponents with a time period of less than 10 years remain for all analysis variables.

\section{Results}

\subsection{The AO/AAO-Sr correlations}

First, correlations between the AO/AAO signals and the $\mathrm{Sr}$ content from January to December were checked, with the time lag of $\mathrm{Sr}$ content varying from 0 to 4 months. For comparison, three AAO indices were checked, based on SLPs of the ERA40 reanalysis, NCEP/NCAR reanalysis, and HadSLP2 datasets. Here, all the time series were confined to the same period (1958 to 1993). Out of all the seasons, significant correlations were observed only during boreal and austral winters, i.e., the strongest AO-coral correlation occurred in January and the strongest AAO-coral correlation occurred 
(a) Reg. (Jan. SLP, Mar. -Sr)

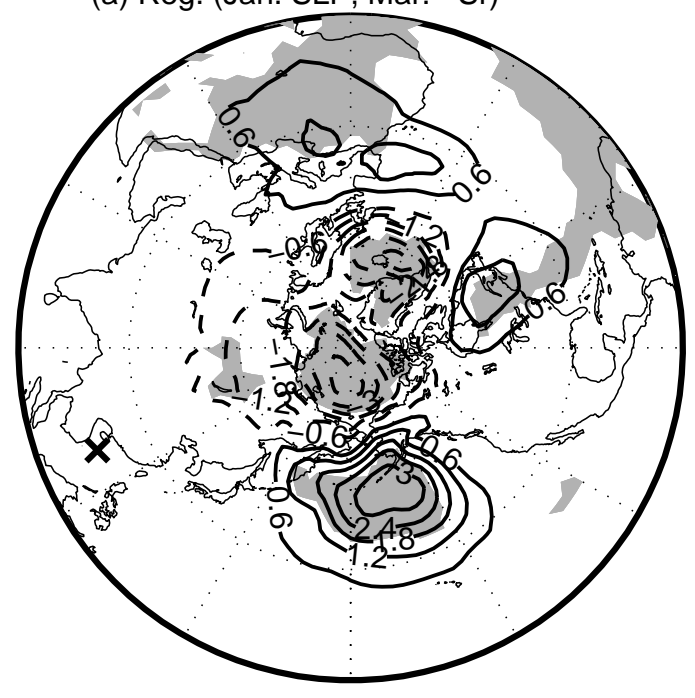

(b) Reg. (Aug. SLP, Nov. -Sr)

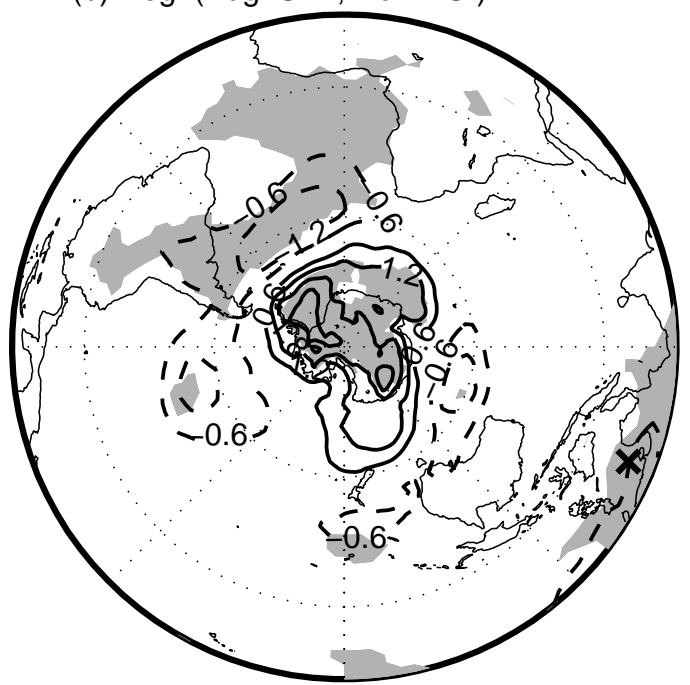

Fig. 3. Regression coefficients of the ERA40 SLP upon the Sr-content time series during 1958-1993. (a) January SLP upon March Srcontent, (b) August SLP upon November Sr-content time series. Positive contours are indicated by solid lines, and the negative contours are indicated by dashed lines. Zero contours are omitted for simplicity. The unit is hPa per standard deviation of Sr. Prior to analysis, the Niño3.4 SST signals were excluded from Sr-content time series. For convenience, the Sr content values were multiplied by -1 so that the results correspond to positive Sr-SST anomalies. The cross denotes the location of Xisha coral site. The shaded area indicates the 0.05 level of significance.

in August (Fig. 2 and Table 1). In other seasons, no evident signals can be identified. Previous studies indicated that the AO and AAO are most active in each hemisphere during winter (Thompson and Wallace, 2000). The most likely implication is that for the season-dependent relations, only the most active AO/AAO signals can influence the climate of the South China Sea (particularly the Sr-SST); this influence would consequently be recorded in the coral proxy. The changes in the $\mathrm{Sr}$ content follow polar signals with a time lag of a few months. Table 1 illustrates Pearson's correlations of the $\mathrm{Sr}$ content with the January AO and the August AAO. It is clear that following the January AO, the corresponding $\mathrm{Sr}$ content in the South China Sea evidently decreases over time; a significant minimum appears in March with $r=-0.46$, significant at the $99 \%$ confidence level. Meanwhile, the maximum $\mathrm{Sr}$ correlations with the August AAO indices derived from ERA40 reanalysis, NCEP/NCAR reanalysis, and HadSLP2 datasets all appear around November. These time lags may result from the fact that both the responses of coral growth to SST and the adjustment of the open ocean SST to atmospheric changes occur over a period of time. Thus, the influence of the January AO on coral is recorded in March. Further, the August AAO signals from more distant high latitudes in the Southern Hemisphere would require a slightly longer time to be recorded in the coral, thereby resulting in a maximum correlation in October-November.

It is interesting to note that the AAO index derived from the ERA40 SLP shows the highest correlation, i.e., $r=+0.49$ (significant at the $99 \%$ level), which is a much stronger relationship than the other two SLP datasets $(r=+0.40$ for HadSLP2 and $r=+0.39$ for NCEP/NCAR). This implies that in order to select atmospheric data, caution should be exercised, particularly when dealing with AAO and Southern Hemisphere circulations. However, Marshall (2003) indicates that the ERA40 SLP would better present atmospheric circulation variability in the Southern Hemisphere.

\subsection{Atmospheric circulation}

The above analysis demonstrated the strong association between the AO/AAO and the $\mathrm{Sr}$ content in the South China Sea, as indicated by the strong correlations. It should be noted that $\mathrm{AO}$ and $\mathrm{AAO}$ are the planetary modes in atmospheric circulation variability in the mid-high latitudes in each hemisphere. This influence, if physically existing, should be supported by large-scale climate anomalies within the context of coral proxies. In order to delineate this phenomenon, changes in lower-middle troposphere circulations were investigated by computing the regression coefficients of the SLP, wind vectors at the 850-hPa level, and 500-hPa geopotential heights upon the $\mathrm{Sr}$ content.

The changes in the SLPs clearly indicate well-defined spatial patterns on hemispheric scales (Fig. 3). For enhanced clarity, in this study, the circulations are shown in such a manner that they correspond to positive Sr-SST anomalies. In association with an one-standard-deviation-lower $\mathrm{Sr}$ 

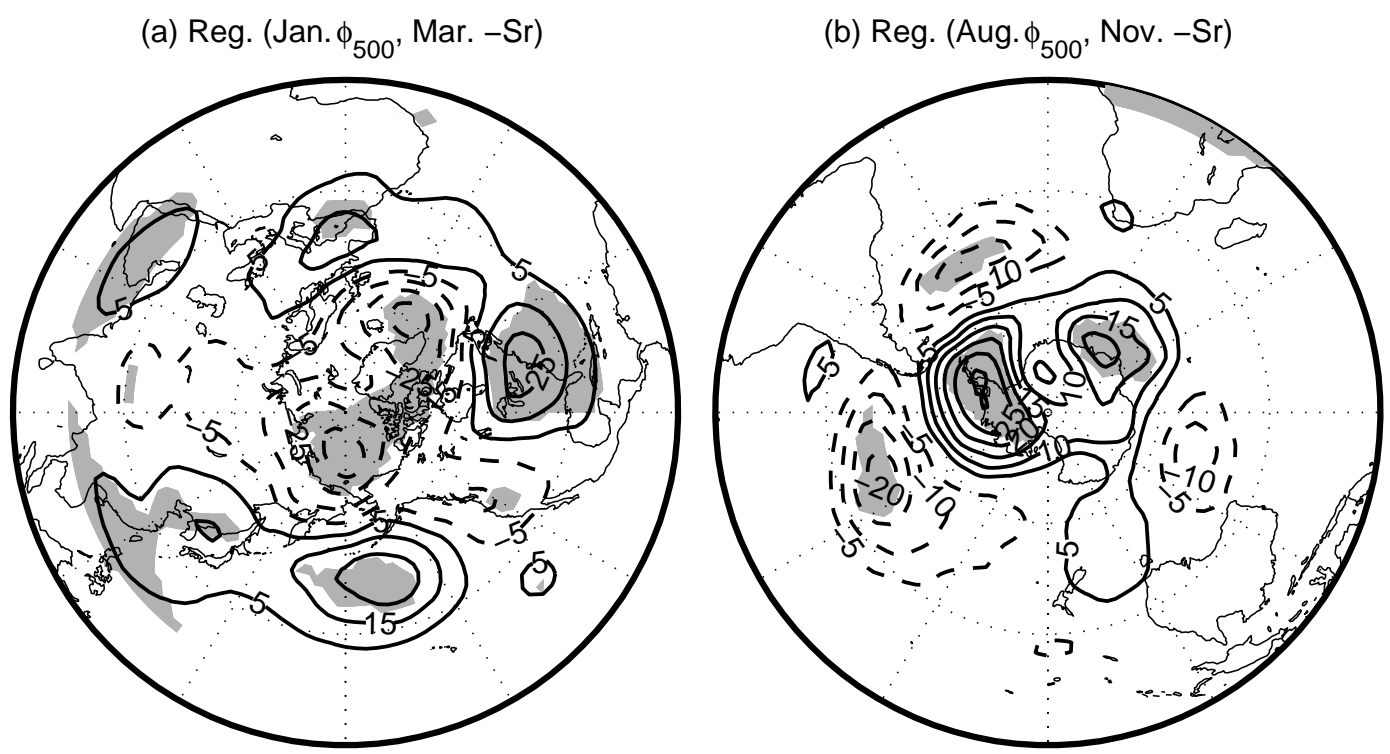

Fig. 4. Same as Fig.3, but for $500 \mathrm{hPa}$ heights. Unit: $\mathrm{m}$.

content (i.e., higher Sr-SST) in March, the SLP in January is +1 to $+3 \mathrm{hPa}$ higher in the North Pacific and +0.6 to $+1.2 \mathrm{hPa}$ higher from Northeastern North America across Southern Europe and Northern Africa. At the same time, a concurrent decrease in pressure was observed over the Arctic Ocean and its vicinity. This anomalous SLP structure evidently resembles the general structure of positive-phase AOrelated pressure anomalies (Thompson and Wallace, 1998, 2000). In the Southern Hemisphere, and in association with the Sr content in November, the SLP changes in August display annular-like characteristics in the mid-high latitudes. As shown in Fig. 3b, when the Sr content is decreased by one standard deviation the SLPs over Antarctica are increased by approximately +0.6 to $+1.8 \mathrm{hPa}$, while pressures at approximately $30^{\circ} \mathrm{S}-50^{\circ} \mathrm{S}$ are decreased by about -0.6 to $-1.2 \mathrm{hPa}$. These findings are consistent with a negativephase AAO pattern (Gong and Wang, 1998, 1999; Thompson and Wallace, 2000).

Concurrently, the annular-like patterns also appear in the middle troposphere at 500-hPa heights over the Northern Hemisphere in January and over the Southern Hemisphere in August, which are associated with the Sr content in March and November, respectively. As shown in Fig. 4a, the positive centers of height anomalies in the Northern Hemisphere are located in zonally oriented regions along East Asia to northern Pacific, and Eastern Northern America to Northern Africa. And a negative center is located in the northern Polar regions. In Fig. $4 \mathrm{~b}$, the centers of negative anomalies appear in the Southern Oceans at $30^{\circ}-50^{\circ} \mathrm{S}$, with opposite anomalies around Antarctica. These anomalies are manifestations of $\mathrm{AO}$ and AAO patterns in the Northern and Southern Hemispheres, respectively. In addition, the locations of these anomalous centers at 500-hPa heights are similar to those in the SLP fields (see Fig. 3), suggesting that coral-polar circulation relations are not confined within the SLP field and that these relations should be understood in the context of the barotropic structure anomalies of the AO and AAO.

Near-surface atmospheric circulations directly influence the surface climate. Accompanied by large-scale pressure anomalies, there are consistent horizontal wind changes at the lower troposphere levels. Figure 5a illustrates the changes in wind vectors at the 850-hPa level (approximately $1.5 \mathrm{~km}$ above sea level) in January in association with the $\mathrm{Sr}$ content. It is evident that horizontal winds are characterized by a dominant anomalous meridional circulation. During years with a lower Sr content (i.e., higher Sr-SST), an anomalous south wind is observed over East Asia, spanning from the South China Sea to $60^{\circ} \mathrm{N}$ along approximately $110^{\circ}-120^{\circ} \mathrm{E}$, suggesting a weaker East Asian winter monsoon, which is climatologically characterized by strong northern winds. Smaller northern winds are also consistent with changes in circulation at the middle troposphere. Figure 4a shows that at higher Sr-SST levels in January, positive anomalies are observed at 500-hPa heights in East Asia, suggesting a weaker East Asian trough and weaker northern winds from the middle latitudes of East Asia to the South China Sea along the rear side of the trough. Previous studies revealed that during winters with negative AO, the East Asian winter monsoon gets stronger, resulting in an anomalous northern wind over the whole of eastern China; in contrast, an anomalous southern wind is dominant in positive AO winters (Gong et al., 2001; Wu and Wang, 2002; Jeong and Ho, 2005). Evidently, the wind changes illustrated in Fig. 5a are indicative of positive AO-related circulation 


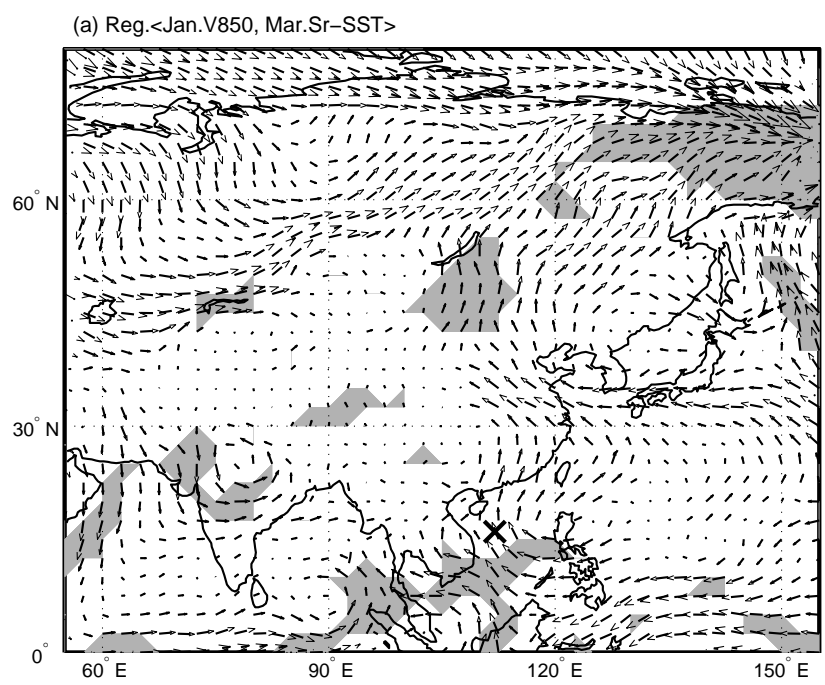

(b) Reg.<Aug.V850, Nov. Sr-SST>

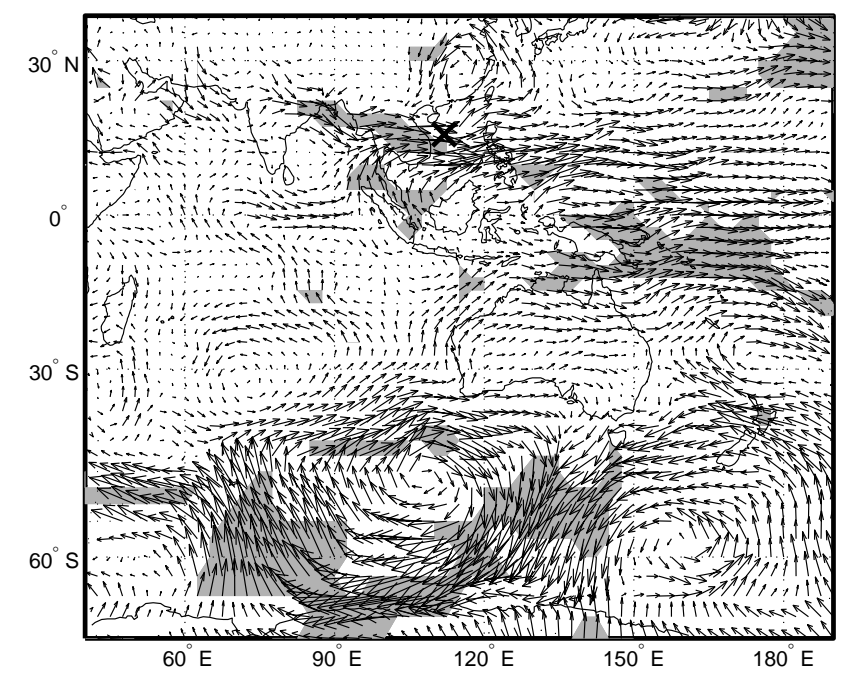

Fig. 5. Regression coefficients of (a) January $850 \mathrm{hPa}$ horizontal winds upon the $\mathrm{Sr}$ content in March, (b) August $850 \mathrm{hPa}$ horizontal winds upon the Sr content in November. The data period is 19581993. The shaded area indicates the 0.05 level of significance. The cross indicates the location of the Xisha coral site. For convenience, the $\mathrm{Sr}$ content values were multiplied by -1 so that the results correspond to positive Sr-SST anomalies. Maximum wind vectors are $2.56 \mathrm{~m} / \mathrm{s}$ and $1.72 \mathrm{~m} / \mathrm{s}$ in (a) and (b), respectively.

changes. Figure $5 \mathrm{~b}$ shows the wind changes at the $850-\mathrm{hPa}$ level in August in association with the Sr contents. The dominant feature is that there are anomalous southern and southwestern winds toward the south of the coral location in the South China Sea. The south and southwestern winds can be traced to the southeastern Indian Ocean, where they initially move toward the northwest, then turn north, and then head east after crossing the Equator in the western Indian Ocean. It is interesting to note that Xue et al. (2004) reported the link between the pressure system in the southern Indian
Table 2. Correlation of boreal/austral winter $\delta^{18} \mathrm{O}$ with ERA40 $\mathrm{AO} / \mathrm{AAO}$.

\begin{tabular}{cccccc}
\hline \multicolumn{5}{c}{$\delta^{18} \mathrm{O}$ with time lags (months) } \\
& +0 & +1 & +2 & +3 & +4 \\
\hline $\begin{array}{c}\text { Bali, 1958-1989 } \\
\text { January AO }\end{array}$ & $+0.59^{\mathrm{a}}$ & $+0.47^{\mathrm{a}}$ & +0.14 & +0.07 & -0.09 \\
$\begin{array}{l}\text { June AAO } \\
-0.12\end{array}$ & -0.28 & $-0.50^{\mathrm{a}}$ & -0.04 & -0.19 \\
Bunaken, 1958-1989 & & & & \\
December AO & $+0.47^{\mathrm{a}}$ & $+0.59^{\mathrm{a}}$ & $+0.49^{\mathrm{a}}$ & $+0.36^{\mathrm{b}}$ & $+0.32^{\mathrm{c}}$ \\
June AAO & $-0.32^{\mathrm{c}}$ & $-0.38^{\mathrm{b}}$ & -0.27 & -0.07 & +0.04 \\
\hline
\end{tabular}

${ }^{\mathrm{a}} p<0.01 ;{ }^{\mathrm{b}} p<0.05 ;{ }^{\mathrm{c}} p<0.1$.

Ocean and the East Asian summer monsoon and, similarly, they emphasized the importance of cross-equatorial air flow originating from the Southern Hemisphere. Figures $3 b$ and $5 \mathrm{~b}$ suggest that in association with the negative-phase AAO, there are anomalous southern/southwestern winds in tropical East Asia, which are related to the negative Sr anomalies (i.e., warmer Sr-SST) in the South China Sea.

Therefore, it can be concluded that a positive AO in January tends to be linked with a weaker East Asian winter monsoon and a weaker northern wind in east China, thereby resulting in a higher temperature in the South China Sea and a higher Sr-SST around 1-2 months later, which will be recorded as a lower $\mathrm{Sr}$ content. Conversely, a negative August AAO is linked to stronger south and southwest winds in the South China Sea. Subsequently, a significantly warmer Sr-SST is expected from September to November and recorded as a lower $\mathrm{Sr}$ content in the coral at that location.

\subsection{Comparison with oxygen isotope records in neigh- boring ocean}

If the regional response of the oceanic climate to AO/AAO is physically robust, the same response should be observed at other coral proxies in the neighboring areas. To test the robustness of this relationship, oxygen isotope $\left(\delta^{18} \mathrm{O}\right)$ records were analyzed for two sites in Indonesia: Bali $\left(8.25^{\circ} \mathrm{S}, 115.5^{\circ} \mathrm{E}\right)$ and Bunaken $\left(1.5^{\circ} \mathrm{N}, 124.83^{\circ} \mathrm{E}\right)$, two high-resolution coral proxies nearest to the Xisha site (see Fig. 1). The two proxies are of monthly resolution, spanning from 1782 to 1989 and 1860 to 1989 , respectively. Note that $\delta^{18} \mathrm{O}$ records in the western Pacific are related to SST, precipitation, or a combination of both (Charles et al., 2003).

The above analysis was repeated using $\delta^{18} \mathrm{O}$ data. The maximum correlations between $\mathrm{AO} / \mathrm{AAO}$ and $\delta^{18}$ and the corresponding time lags are presented in Table 2. For boreal winter oxygen isotope records in Bali coral, the maximum correlation between $\mathrm{AO}$ and $\delta^{18} \mathrm{O}$ appears in January, with $r=+0.59$. A significant $r$ value of +0.47 exists when the 
Table 3. Correlation of coral proxies with station-based AAO in 1958-1989.

\begin{tabular}{rccccc}
\hline & \multicolumn{5}{c}{ Proxy time lags (months) } \\
& +0 & +1 & +2 & +3 & +4 \\
\hline Xisha Sr with August AAO & +0.01 & +0.18 & +0.24 & $+0.27^{\mathrm{a}}$ & +0.10 \\
Bali $\delta^{18} \mathrm{O}$ with June AAO & -0.04 & -0.21 & -0.24 & +0.16 & -0.06 \\
Bunaken $\delta^{18} \mathrm{O}$ with June AAO & -0.19 & $-0.30^{\mathrm{a}}$ & $-0.30^{\mathrm{a}}$ & -0.18 & -0.10 \\
\hline
\end{tabular}

${ }^{\mathrm{a}} p<0.1$.

January AO is correlated with February $\delta^{18} \mathrm{O}$. As the time lag increases, the correlation gradually weakens, suggesting a relatively quick change in Bali coral $\delta^{18} \mathrm{O}$ in simultaneous month and one month later in response to January AO. For the Bunaken site $\delta^{18} \mathrm{O}$, the strongest relationship appears for the December AO, the correlations with $\delta^{18} \mathrm{O}$ from December to April are all significant, and a maximum of $r=+0.59$ appears for the January $\delta^{18} \mathrm{O}$. These two $\delta^{18} \mathrm{O}$ time series show a similar relation to winter AO. During austral winter, significant relations between $\mathrm{AAO}$ and $\delta^{18} \mathrm{O}$ are evident as well. Both the Bali and Bunaken coral proxies show the strongest connection to June AAO, minimums $(r=-0.50$ and $r=-0.38$ ) appear in August and July $\delta^{18} \mathrm{O}$ at the Bali and Bunaken sites, respectively.

These analyses indicate significant associations of $\delta^{18} \mathrm{O}$ with $\mathrm{AO}$ in boreal winters and with $\mathrm{AAO}$ in austral winters, again suggesting that $\mathrm{AO} / \mathrm{AAO}$ has a noticeable influence on precipitation/SST over the South China Sea. Relatively shorter observations from sparse meteorological stations in northern Australia, Indonesia, and their neighboring islands displayed evidence that precipitation and/or temperature are correlated with the AAO (Gillett et al., 2006; Meneghini et al., 2007). Therefore, it is highly likely that AO and AAO relations at the Xisha, Bali, and Bunaken coral proxies are manifestations of a regional scale response, although the involved mechanisms are not fully understood.

\section{Discussions}

As indicated in the previous studies the quality of SLP data in mid-high latitudes of the Southern Hemisphere is a subtle issue. In particular, a distorted AAO-coral relationship might be yielded from inaccurate SLP datasets, including reanalysis SLPs (for example, reanalysis SLPs prior to 1979) and interpolated HadSLP2 in early time periods. Ideally, reliable SLP observations should be used with full spatial coverage over the Southern Hemisphere and with sufficient time spans for analysis. However, to this day, no such datasets are available. Marshall (2003) released an observation-based AAO time series beginning in 1957 and based on monthly SLP records obtained from 12 stations at mid-high latitudes in the Southern Hemisphere. The relation to coral proxies would be helpful to assess the uncertainty of the AAO-coral relationship resulting from reanalysis SLPs. Therefore, the analysis was repeated using the station-based AAO index. Table 3 illustrates the correlations between the observationbased AAO and three different proxies. The correlation of the August AAO with Xisha site coral in later months increases gradually from +0.18 in September to a maximum of +0.27 in November. Similar correlations can be found in $\delta^{18} \mathrm{O}$ data obtained from Bali and Bunaken corals. For the Bali coral proxy, the AAO in June has a strongest correlation, $r=-0.24$, with $\delta^{18} \mathrm{O}$ in September. Meanwhile, at Bunaken, the strongest correlations with $\delta^{18} \mathrm{O}, r=-0.30$, appear in July and August. It is clear that all the strongest relationships between station-based AAO and coral proxies appear with a lag of 1-3 months in the three coral time series. These features are generally similar to those of ERA40 data, and the consistent results again support the robustness of the AO/AAO-coral proxy relations. Note that the correlations in Table 3 are evidently smaller than those obtained from the ERA40 reanalysis data (see Tables 1 and 2). This may be partly due to the sparsity of station SLPs at mid-high latitudes in the Southern Hemisphere. When more station SLPs become available in the future, our understanding of the AAO-coral connection would be improved by using a more representative observation-based AAO index.

The stability of the Sr-AO/AAO relationship was also checked by extending the analysis data length based on HadSLP2 pressure data. As indicated in Fig. 6, the correlations tend to decrease as more early-period data are utilized. Meanwhile, the general features are similar, i.e., the strongest correlations appear with a time lag of a few months. The AO$\mathrm{Sr}$ relations are more stable than the AAO-Sr relations. The correlations between the January AO and the $\mathrm{Sr}$ content are very similar for the three data periods; all reach a maximum in March. The AAO-Sr correlations, however, show a moderate difference among different time periods. The correlations are moderately weaker than those from the most recent decades, and correlation maxima appear in September when pre-1920s data are used. This may indicate a large uncertainty in SLP data in the Southern Hemisphere where pressure observations from early periods are quite sparse (Allan and Ansell, 2006). The pressure observations in the Northern Hemisphere are considerably more accurate. Thus, if 
(a) AO Jan.

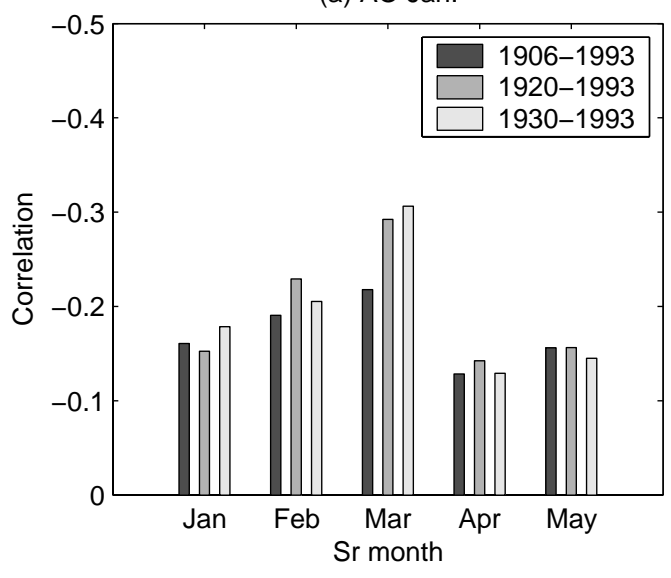

(b) AAO Aug.

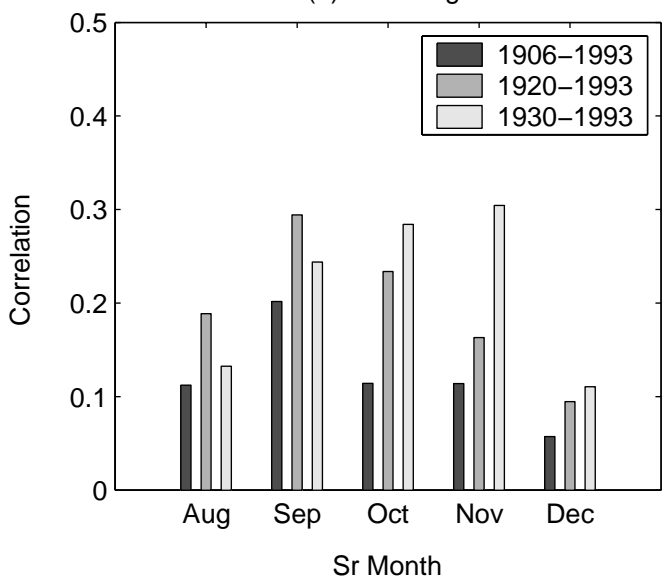

Fig. 6. Correlation between $\mathrm{Sr}$ and AO/AAO during different time periods. (a) January AO with Sr, (b) August AAO (HadSLP2) with Sr.

the coral-AO/AAO correlation is stable over time, the teleconnections can be harnessed to reconstruct historical AO and AAO indices after their relations are carefully calibrated and verified. Previous reconstructions of AO and AAO rely heavily on the warm-season tree-ring net in the mid-high latitude regions (D'Arrigo et al., 2003; Jones and Widmann, 2003); this more reliably represents the high-frequency variability in growth seasons. Preliminary investigations indicate that coral proxies in the South China Sea can be used for reconstructing low-frequency variations in historical atmospheric circulations (Peng et al., 2003). Although reliable climate records can be derived from a limited number of coral core samples (Stephans et al., 2004), the variance determined from a single proxy is often somewhat low. Additional coral time-series would hopefully result in a significant increase in the variance in reconstructed climate signals. Therefore, when used to reconstruct the historical AO and AAO variations, particularly low-frequency variations, the global coral net could provide additional skills.

It is interesting to note that, as shown in Fig. $5 b$, there is a cyclonic circulation anomaly located in the southernmost part of mainland China. This type of circulation anomaly implies a precipitation anomaly in that region. For example, Nan and Li (2003) found that boreal summer precipitation along the Yangtze River valley is correlated to the April-May AAO. It is well known that the East Asian summer monsoon season is closely linked to regional SST variations in the South China Sea and the tropical western Pacific (Nitta and Hu, 1996; Lau et al., 2000; Yoo et al., 2004). Preliminary studies revealed a negative correlation between AAO and temperature in northern Australia, and a positive relation with precipitation (Gillett et al., 2006; Meneghini et al., 2007). In these cases, it is likely that enhanced convection along the equator plays an important role along with the anomalous cross-equator air flow originating from
Southern Hemisphere (Ho et al., 2005). Correspondingly, the meridional wind as a key component of summer monsoon over South China Sea (Liang et al., 2007), and regional atmospheric circulation of northwestern Pacific relating to south hemisphere through teleconnection (e.g., Hines and Bromwich, 2002) both may influence East Asian summer monsoon. Clarifying issues such as how the East Asian monsoonal circulation is involved in or influenced by AO and $\mathrm{AAO}$, and what is the role of the South China Sea/west Pacific SST caused by the AO and AAO, would provide important information for a better understanding of East Asian monsoon variability and prediction. The coral proxy provides an opportunity for this study, beyond the very short periods of modern meteorological/oceanic observations in the South China Sea.

\section{Summary}

Using the climate proxies of $\mathrm{Sr}$ and $\delta^{18} \mathrm{O}$ from three coral sites in the South China Sea, a study was conducted of the statistical relationship between tropical climate proxies and $\mathrm{AO} / \mathrm{AAO}$ after the possible influence of ENSO was removed, focusing on interannual timescale variations. For the Xisha site coral records, the strongest AO-Sr and AAO-Sr connections appear in January and August, respectively. Their maximum correlations occur when the proxies lag AO/AAO by about 2-3 months. For the $\delta^{18} \mathrm{O}$ time series at the Bali and Bunaken sites, the maximum correlations with $\mathrm{AO}$ occur in January and December, respectively. Their maximum correlations with AAO both appear in June. In association with the local proxy variations, the hemispheric meteorological fields change on a large scale. Regression of SLPs and 500$\mathrm{hPa}$ heights with respect to the Xisha $\mathrm{Sr}$ time series yields annular-like patterns with barotropic vertical structures. At lower tropospheric levels, concurrent wind anomalies appear 
over the South China Sea at $850 \mathrm{hPa}$. These anomalies seem to indicate that following positive $\mathrm{AO}$ in boreal winter, northern winds in East Asia become weaker, the Sr content over the South China Sea tends to be lower than normal, and $\delta^{18} \mathrm{O}$ at the Bali and Bunaken sites rises. Following positive AAO in austral winter, the $\mathrm{Sr}$ content tends to rise and $\delta^{18} \mathrm{O}$ values tend to fall. These findings help to better understand monsoon climates (particularly in the South China Sea) and their teleconnection to high-latitude climate changes.

Acknowledgements. This study was supported by the PE09030 of Korea Polar Research Institute, NSFC-40675035, 2008AA121704 and GYHY200706010 programs. C.-H. Ho was supported by CATER 2006-4204. ECWMF reanalysis data was obtained from the ECMWF server at http://data.ecmwf.int. The authors wish to thank Y. Sun for providing Sr-content time-series data. Comments from the two anonymous reviewers are appreciated.

Topical Editor F. D'Andrea thanks two anonymous referees for their help in evaluating this paper.

\section{References}

Allan, R. J. and Ansell, T. J.: A new globally complete monthly historical mean sea level pressure data set (HadSLP2): 18502004, J. Climate, 19, 5816-5842, 2006.

Charles, C. D., Cobb, K., Moore, M. D., and Fairbanks, R. G.: Monsoon-tropical ocean interaction in a network of coral records spanning the 20th century, Mar. Geology, 201, 207-222, 2003.

Charles, C. D., Hunter, D. E., and Fairbanks, R. G.: Interaction between the ENSO and the Asian monsoon in a coral record of tropical climate, Science, 277, 925-928, 1997.

D’Arrigo, R. D., Cook, E. R., Mann, M. E., and Jacoby, G. C.: Tree-ring reconstructions of temperature and sea-level pressure variability associated with the warm-season Arctic Oscillation since AD 1650, Geophys. Res. Lett., 30, 1549, doi:10.1029/2003GL017250, 2003.

Fan, K. and Wang, H. J.: Antarctic oscillation and the dust weather frequency in north China, Geophys. Res. Lett., 31, L010201, doi:10.1029/2004GL019465, 2004.

Gillett, N. P., Kell, T. D., and Jones, P. D.: Regional climate impacts of the Southern Annular Mode, Geophys. Res. Lett., 33, L23704, doi:10.1029/2006GL027721, 2006.

Gong, D. Y. and Ho, C. H.: Intra-seasonal variability of wintertime temperature over east Asia, Int. J. Climatol., 24, 131-144, 2004.

Gong, D. Y., Wang, S. W., and Zhu, J. H.: East Asian winter monsoon and Arctic Oscillation, Geophys. Res. Lett., 28, 2073-2076, 2001.

Gong, D. Y. and Wang, S. W.: Antarctic Oscillation: Concept and applications, Chinese Sci. B., 43(9), 734-738, 1998.

Gong, D. Y. and Wang, S. W.: Definition of Antarctic Oscillation Index, Geophys. Res. Lett., 26, 459-462, 1999.

Hines, K. M. and Bromwich, D. H.: A pole to pole west Pacific atmospheric teleconnection during August, J. Geophys. Res., 107(D18), 4359, doi:10.1029/2001JD001335, 2002.

Ho, C. H., Kim, J. H., Kim, H. S., Sui, C. H., and Gong, D. Y.: Possible influence of the Antarctic Oscillation on tropical cyclone activity in the western North Pacific, J. Geophy. Res., 110, D19104, doi:10.1029/2005JD005766, 2005.
Isoguchi, O. and Kawamura, H.: El Niño-related offshore phytoplanton bloom events around the Spratly Islands in the South China Sea, Geophys. Res. Lett., 32, L21603, doi:10.1029/2005GL024285, 2005.

Jeong, J. H. and Ho, C. H.: Changes in occurrence of cold surges over East Asia in association with Arctic oscillation, Geophys. Res. Lett., 32, L14704, doi:10.1029/2005GL023024, 2005.

Jones, P. D. and Lister, D. H.: Intercomparison of four different Southern Hemisphere sea level pressure datasets, Geophys. Res. Lett., 34, L10704, doi:10.1029/2007GL029251.

Jones, J. M. and Widmann, M.: Instrument- and tree-ring-based estimates of the Antarctic Oscillation, J. Climate, 16, 3511-3524, 2003.

Kalnay, E., Kanamitsu, M., Kistler, R., Collins, W., Deaven, D., Gandin, L., Iredell, M., Saha, S., White, G., Woollen, J., Zhu, Y., Chelliah, M., Ebisuzaki, W., Higgins, W., Janowiak, J., Mo, K. C., Ropelewski, C., Wang, J., Leetmaa, A., Reynolds, R., Jenne, R., and Joseph, D.: The NCEP/NCAR 40-year reanalysis project, B. Am. Meteorol. Soc., 77, 437-431, 1996.

Lau, K. M., Kim, K. M., and Yang, S.: Dynamical and boundary forcing characteristics of regional components of the Asian summer monsoon, J. Climate, 13, 2461-2482, 2000.

Liang, J., Yang, S., Li, C., and Li, X.: Long-term changes in the South China Sea summer monsoon revealed by station observations of the Xisha Islands, J. Geophys. Res., 112, D10104, doi:10.1029/2006JD007922, 2007.

Lu, R. Y., Li, Y., and Dong, B. W.: Arctic oscillation and Antarctic oscillation in internal atmospheric variability with an ensemble AGCM simulation, Adv. Atmos. Sci., 24, 152-162, 2007.

Marshall, G. J. and Harangozo, S. A.: An appraisal of NCEP/NCAR reanalysis MSLP data viability for climate studies in the South Pacific, Geophys. Res. Lett., 27, 3057-3060, 2000.

Marshall, G. J.: Trends in Antarctic geopotential height and temperature: A comparison between radiosonde and NCEP-NCAR reanalysis data, J. Climate, 15, 659-674, 2002.

Marshall, G. J.: Trends in the southern annular mode from observations and reanalyses, J. Climate, 16, 4134-4143, 2003.

Meneghini, B., Simmonds, I., and Smith, I. N.: Association between Australian rainfall and the Southern Annular Mode, Int. J. Climatol., 27, 109-121, 2007.

Miller, A. J., Zhou, S., and Yang, S. K.: Relationship of the Arctic and Antarctic Oscillations to the outgoing longwave radiation, J. Climate, 16, 1583-1592, 2003.

Nakamura, T., Tachibana, Y., Honda, M., and Yamane, S.: Influence of the northern hemisphere annular mode on ENSO by modulating westerly wind bursts, Geophys. Res. Lett., 33, L07709, doi:10.1029/2005GL025432, 2006.

Nan, S. and Li, J. P.: The relationship between summer precipitation in the Yangtze River valley and boreal spring southern hemisphere annular mode, Geophys. Res. Lett., 20, 2266, doi.10.1029/2003GL018381, 2003.

Nitta, T. and Hu, Z. Z.: Summer climate variability in China and its association with $500 \mathrm{hPa}$ height and tropical convection, J. Meteor. Soc. Japan, 74, 425-445, 1996.

Peng, Z., Chen, T., Nie, B., Head, M. J., He, X., and Zhou, W.: Coral $18 \mathrm{O}$ records as an indicator of winter monsoon intensity in the South China Sea, Quat. Res., 59, 285-292, 2003.

Rimbu, N., Lohmann, G., Felis, T., and Pätzold, J.: Arctic Oscillation signature in a Red Sea coral, Geophys. Res. Lett., 28, 2959- 
2962, 2001.

Stephans, C. L., Quinn, T. M., Taylor, F. W., and Corrége, T.: Assessing the reproducibility of coral-based climate records, Geophys. Res. Lett., 31, L18210, doi:10.1029/2004GL020343,2004.

Sun, Y., Sun, M., Wei, G., Lee, T., Nie, B., and Yu, Z.: Strontium contents of a Porites coral from Xisha Island, South China Sea: A proxy for sea-surface temperature of the 20th century, Paleoceanography, 19, PA2004 doi:10.1029/2003PA000959, 2004.

Thompson, D. W. J. and Wallace, J. M.: The Arctic Oscillation signature in the wintertime geopotential height and temperature fields, Geophys. Res. Lett., 25, 1297-1300, 1998.

Thompson, D. W. J. and Wallace, J. M.: Annular modes in the extratropical circulation, part I: Month-to-month variability, J. Climate, 13, 1000-1016, 2000.

Thompson, D. W. J. and Lorenz, D. J.: The signature of the annular modes in the tropical troposphere, J. Climate, 17, 4330-4342, 2004.

Tudhope, A. W., Shimmield, G. B., Chilcott, C. P., Jebb, M., Fallick, A. E., and Dalgleish, A. N.: Recent changes in climate in the far western equatorial Pacific and their relationship to Southern Oscillation: oxygen isotope records from massive corals, Papua New Guinea, Earth Planet. Sci. Lett., 136, 575-590, 1995.
Uppala, S. M., Kallberg, P. W., Simmons, A. J., Andrae, U., da Costa Bechtold, V., Fiorino, M., Gibson, J. K., Haseler, J., Hernandez, A., Kelly, G. A., Li, X., Onogi, K., Saarinen, S., Sokka, N., Allan, R. P., Andersson, E., Arpe, K., Balmaseda, M. A., Beljaars, A. C. M., van de Berg, L., Bidlot, J., Bormann, N., Caires, S., Chevallier, F., Dethof, A., Dragosavac, M., Fisher, M., Fuentes, M., Hagemann, S., Holm, E., Hoskins, B. J., Isaksen, L., Janssen, P. A. E. M., Jenne, R., McNally, A. P., Mahfouf, J.-F., Morcrette, J.-J., Rayner, N. A., Saunders, R. W., Simon, P., Sterl, A., Trenberth, K. E., Untch, A., Vasiljevic, D., Viterbo, P., and Woollen, J.: The ERA-40 re-analysis, Q. J. Roy. Meteorol. Soc., 131, 2961-3012, 2005.

Wu, B. Y. and Wang, J.: Winter Arctic Oscillation, Siberian High and east Asian winter monsoon, Geophys. Res. Lett., 29, 1897, doi:10.1029/2002GL015373, 2002.

Xue, F., Wang, H. J., and He, J. H.: Interannual variability of Mascarene High and Australian High and their influence on East Asian summer monsoon, J. Meteo. Soc. Japan, 82, 1178-1186, 2004.

Yang, S., Lau, K. M., and Kim, K. M.: Variations of the east Asian jet stream and Asian-Pacific-American winter climate anomalies, J. Climate, 15, 306-325, 2002.

Yoo, S. H., Ho, C. H., Yang, S., Choi, H. J., and Jhun, J. G.: Influences of tropical-western and extratropical Pacific sea surface temperatures on the east and Southeast Asian climate in the summers of 1993-94, J. Climate, 17, 2673-2687, 2004. 